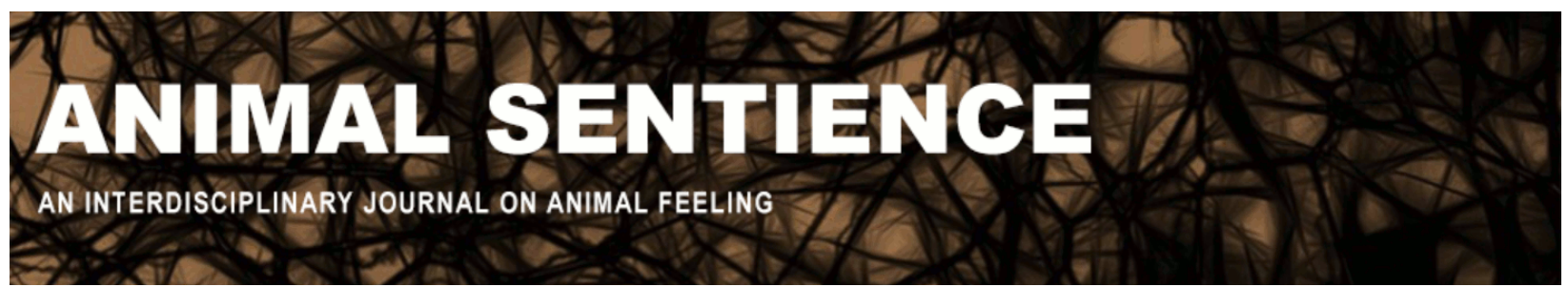

Price, Catherine (2019) Human and nonhuman animals: Towards equality. Animal Sentience 23(34)

DOI: $10.51291 / 2377-7478.1414$

Date of submission: 2019-02-11

Date of acceptance: 2019-02-20

(c)

This article has appeared in the journal Animal

Sentience, a peer-reviewed journal on animal

cognition and feeling. It has been made open access,

free for all, by WellBeing International and deposited

in the WBI Studies Repository. For more information,

please contact

wbisr-info@wellbeingintl.org.

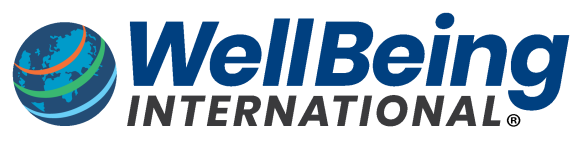

SOLUTIONS FOR PEOPLE, ANIMALS AND ENVIRONMENT 


\title{
Human and nonhuman animals: Towards equality
}

Commentary on Chapman \& Huffman on Human Difference

\author{
Catherine Price \\ Sociology Department, University of Warwick, UK
}

\begin{abstract}
Chapman \& Huffman argue that we should not consider humans as unique and superior to nonhuman animals. Ecofeminism advocates the respectful treatment of humans, nonhuman animals, and the environment.
\end{abstract}

\begin{abstract}
Catherine Price, doctoral student in Sociology, University of Warwick, does research in science communication and public engagement with science through the media. She is also interested in the representation of food in the media, and in cultural theories that question and challenge existing relationships between humans, animals, and the environment. Website
\end{abstract}

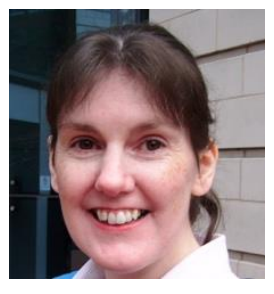

\section{.}

1. Introduction. Chapman \& Huffman (2018) (C \& H) argue for a change in how we perceive other species. Instead of viewing humans as superior to nonhuman animals, we should view them as equals. C \& H contend that humans continue to put profits before nonhuman animals and the ecosystems that support them. I believe that drawing on sociological thought can help our thinking about the relationships between human and nonhuman animals.

2. Borders between species. An analytic order is imposed on the natural world by splitting fauna into different types of beings, creating borders between species. As Dawkins (2012, p. 183) notes, "we are up against culture, religion, and a widespread and deep-seated conviction among many people that humans are much more important than any animal." The hegemonic discourses which depend on what it means to be "human" or "animal" sustain the human/cultural subject against the animal/natural object. Plumwood (2012) describes the human/nature dualism as a product of thousands of years of Western culture according to which nonhuman animals exist only as a resource for our species; they and the ecosystems to which they belong are there to be exploited by us. The social construction of nonhuman animals influences the way they are treated in human society. Our power is coercive, as nonhuman animals cannot consent to their treatment. Humans collaborate in this every time they purchase animal products. This can be withdrawn at any time by boycotting products such as battery farm eggs or cosmetics tested on animals and becoming vegetarian or vegan.

3. Mainstream animal ethics theories. The mainstream animal ethics theories have helped to break down the assumption that feelings, communicative capacity, and ethics apply only to humans and not nonhuman animals. According to Singer's (2015) utilitarian view of "animal liberation," humans have a responsibility for nonhuman animals. People have a duty to act to bring about the best consequences for all. In this view, nonhuman animals can still suffer, as suffering is the necessary price for bringing about the best consequences for all. In contrast, Regan (2004) takes an "animal rights" perspective: What is right does not depend on the best 
consequences for all but on the respectful and appropriate treatment of the individual. In this approach, the human exploitation of nonhuman animals is abolished altogether, whether on the farm, in the wild, or in the research lab. Both views consider nonhuman animals as individuals with interests, calling for equal consideration of humans and nonhuman animals.

4. The ecofeminist perspective. Instead of focusing on individual nonhuman animals, ecofeminism aims to bridge the distinction by bringing humans, nonhuman animals and nature together. Because humans, nonhuman animals and nature are connected, interdependent and vulnerable, compassion is based on the unity underlying these relationships (Adams 2015, 2018; Plumwood 1997, 2012; Warren 1987, 1990). Ecofeminists object not only to ecological devastation but also to the consumption of the flesh of nonhuman animals.

\section{References}

Adams, C. J. (2015) The Sexual Politics of Meat, 4th ed. London, Bloomsbury Academic. Adams, C. J. (2018) Neither Man nor Beast, 2nd ed. London, Bloomsbury Academic. Chapman, C. A. and Huffman, M. A. (2018) Why do we want to think humans are different? Animal Sentience 23(1).

Dawkins, M. S. (2012) Why Animals Matter. Oxford, Oxford University Press.

Plumwood, V. (1997) Babe: The tale of the speaking meat - Part I. Animal Issues, 1(1), 21-36. Plumwood, V. (2012) The Eye of the Crocodile. Acton, ANU Press.

Regan, T. (2004) The Case for Animal Rights, 2nd ed. Berkeley and Los Angeles, University of California Press.

Singer, P. (2015) Animal Liberation, 3rd ed. London, The Bodley Head.

Warren, K. J. (1987) Feminism and ecology: Making connections. Environmental Ethics, 9(1), 3-20.

Warren, K. J. (1990) The power and the promise of ecological feminism. Environmental Ethics, 12(Summer), 125-146. 